\title{
ALGUNS ASPECTOS QUE FUNDAMENTAM A ASSISTENCIA DE ENFERMAGEM A PACIENTES EM TRAÇÃO
}

\author{
Terezinha Aparecida Neves* \\ Celina de Arruda Camargo* \\ Marlúcia N. Comarú *
}

RBEn/07

NEVES, T.A., CAMARGO, C.A. e COMARÜ M.N. - Alguns aspectos que fundamentam a assistência de enfermagem a pacientes em tração. Rev. Bras. Enf.; DF, 29 : 56-63, 1976.

\section{INTRODUÇAOO}

Dando prosseguimento aos aspectos que englobam a assistência de enfermagem a pacientes com comprometimento do sistema músculo-esquelético, é nosso propósito nesta oportunidade abordar a atuação da enfermeira na assistência do paciente em tração.

Em Traumatologia o atendimento de enfermagem objetiva participar da promoção, manutenção e recuperação da saúde do individuo traumatizado com a finalidade de torná-lo independente, tanto quanto possivel, da ação e ajuda de outros. Desta forma a enfermeira durante o tratamento deve elaborar, participar de execução e supervisionar o plano de assistência de enfermagem que deve ter como objetivo ajudar o paciente a satisfazer suas necessidades e evitar complicaçōes secundárias.

\section{CONCEITUAÇĀO}

O inicio do programa de assistência deve ocorrer quando o paciente é admitido no Hospital e prosseguir durante todo o periodo de internação sujeito naturalmente a reformulaçōes, conforme a evolução do estado do paciente.

A elaboração do plano de atendimento. de enfermagem, deve fundamentar-se nos conhecimentos de enfermagem geral e também nos conhecimentos específicos de traumatologia.

A determinação dos objetivos de enfermagem na assistência do paciente em tração, depende dos propósitos a serem alcançados, entretanto existem alguns: objetivos que podem ser constantes no. atendimento de pacientes com afecçōes traumatológicas, tais como:

1. ajudar o paciente a satisfazer as necessidades condicionadas pela lesão e. pelo tratamento a que é submetido.

2. evitar complicaçōes secundárias conseqüentes da imobilização no leito, im-posta pelo próprio tratamento, tais como:

- diminuição da amplitude artícular - diminuição da força muscular

* Enfermeiras da Divisão de Reabilitação Profissional de Vergueiro - Hospital das Clinicas da Faculade de Medicina da Universidade de São Paulo. 
NEVES, T.A., CAMARGO, C.A. e COMARU M.N. - Alguns aspectos que fundamentam a assistência de enfermagem a pacientes em tração. Rev. Bras. Enf.; DF, 29 : 56-63, 1976.

— instalação de deformidade

- problemas respiratórios

- problemas circulatórios

- distúrbios urológicos

- distúrbios gastro-intestinais

- formação de escaras.

Para alcançar estes objetivos, o programa de assistência de enfermagem deve seguir par e passo o tratamento médico que no caso de imobilização por tração, poderá ou não sofrer algumas alterações no decurso do tratamento. Para assegurar o bom êxito do tratamento a ser oferecido, acreditamos ser oportuno lembrar alguns princípios que norteiam este tipo de tratamento.

a) Imobilização por tração - o princípio da tração aplicada ao corpo humano pode ser entendida como uma força externa e contínua aplicada sobre um segmento corporal, na tentativa de neutralizar a contratibilidade muscular.

Dependendo do tipo de lesão e da região que sofreu o impacto, verificamos no osso, desvio no seu eixo original e conseqüente encurtamento do segmento. Isto se deve por contração de alguns grupos musculares que atuam isoladamente, uma vez que se desfez o equilíbrio entre o ponto de aplicação e o ponto de resistência da força muscular.

b) Tipo de tração - para vencer a resistência muscular e proporcionar a imobilização desejada, o médico ortopedista muitas vezes recorre à tração. Os tipos de tração mais comumente utilizados são: tração óssea e tração através da pele.

A tração da pele atua indiretamente sobre o osso, uma vez que é aplicada sobre a pele; é conseguida mediante a aplicação de tiras adesivas sobre a pele do segmento a ser tracionado. indicada quase sempre para a redução de fraturas em crianças, e para adultos, somente quando deve permanecer por curto espaço de tempo. Este tipo de tração tem algumas desvantagens; não suporta quantidade elevada de peso, e é contra-indicada na presença de lesões de pele e de alergias.
A tração transesquelética é aplicada diretamente sobre o osso, e se faz mediante a passagem de um fio metálico no seu segmento distal. Esta tração tem a vantagem de suportar uma força bastante elevada, sendo portanto freqüentemente indicada no tratamento das fraturas dos membros superiores e membros inferiores de pacientes adultos. Outra vantagem da tração óssea transesquelética é que esta forma de tratamento pode ser mais demorada.

Dadas as suas características, alguns ortopedistas consideram a tração da pele como transitória e a tração óssea como prulongada. Visto, embora de forma genérica, os princípios que fundamentam o tratamento por tração, vejamos suas implicações na assistência de enfermagem.

\section{ASSISTENCIA DE ENFERMAGEM}

1. O paciente face ao traumatismo etratamento

A maioria dos pacientes que necessitam de assistência em hospital traumatológico, são pessoas sadias que devido. a um acidente suas atividades foram abruptamente interrompidas para dar início ao tratamento que suas condiçōes físicas exigem no momento.

Em que esta interrupção de atividade afeta o paciente? Estaria ele preparado. para ausentar-se de seu lar e separar-se de sua família no momento? Como ficaram seus filhos? Seus familiares estão a par do acidente? Quem poderia assumir a responsabilidade de seus filhos e de sua. casa? Quais as informações que o paciente já tem, se as tem, sobre fratura?. O que significa para ele ficar imobilizado por determinado período de tempo? A resposta a estas indagaçōes devem fazer parte das informaçōes que a enfermeira vai utilizar-se para planejar a assistência de enfermagem ao paciente. Quando a enfermeira conhece a reação do paciente face ao problema do traumatismo e do tratamento por tração, é mais pro- 
NEVES, T.A., CAMARGO, C.A. e COMARU M.N. - Alguns aspectos que fundamentam 8 assistência de enfermagem a pacientes em tração. Rev. Bras. Enf.; DF, 29 : 56-63, 1976.

vável que ela consiga sua indispensável cooperação e ajuda durante o tratamento. Utilizando-se de sua habilidade de comunicação a enfermeira deve procurar inteirar-se das preocupaçōes do paciente, suas angústias e ansiedade, a dor física e às vezes moral, e, na medida do possível, procurar atendê-lo nestas necessidades. $\mathrm{Na}$ verdade, muitas vezes ele necessita mais de apoio e compreensão do que de fortes sedativos. Assim atuando a enfermeira estará prestando uma assistência de enfermagem ao cliente que segundo Horta (5) é definida como: "a ciência e a arte de assistir o ser humano (indivíduo, família e comunidade) no atendimento de suas necessidades básicas, de torná-lo independente desta assistência quando possível. pelo ensino do autocuidado; de recuperar, manter e promover sua saúde em colaboração com outros profissionais. Assistir, em enfermagem, é: fazer pelo ser humano tudo aquilo que ele não pode fazer por si mesmo; ajudar ou auxiliar quando parcialmente impossibilitado de se autocuidar, orientá-lo ou ensiná-lo, supervisioná-lo e encaminhá-lo a outros profissionais."

\section{Passagem do fío da tração}

Um paciente que de um momento para o outro é transportado para o hospital, nem sempre está em condições higiênicas adequadas para se submeter a um tratamento médico, seja em razão dos seus hábitos higiênicos ou das sujidades resultantes do próprio acidente.

Remover as sujidades, desde que as condiçōes do paciente o permitem, é um dos primeiros passos para a prevenção ou diminuição de possível contaminação. O preparo da pele consta de limpeza com água e sabão e tricotomia, se necessário, da área onde vai ser introduzido o fio de tração ou aplicado o adesivo.

Enquanto se procede ao preparo da pele deve-se explicar ao paciente: no que consiste a passagem do fio ou aplicação do adesivo; como é feita; o material usa- do; a fraca sensação de dor semelhante à dor causada por introdução de uma agulha de injeção, não sendo portanto, indicado o uso de anestésico.

Após proceder à assepsia, o médico necessitará do seguinte material esterilizało: fio de tração e o aparelho próprio para seu uso; rolha de cortiça; gaze; algodão ortopédico e atadura de crepe. O estribo deve adaptar-se não somente ao fío passado mas também à região corporal submetida ao tratamento.

Quando se trata de tração de esparadrapo o material utilizado é esparadrapo largo, algodão ortopédico, atadura de crepe, um pedaço de madeira medindo aproximadamente $10 \mathrm{~cm} \times 10 \mathrm{~cm}$ com orifício central e cordão de nylon.

Depois do precedimento médico o paciente deve ser acamado.

\section{Transferência do paciente para o leito}

A primeira preocupação quando se rerebe um paciente com tração, é a escolha da cama; esta deve ser ortopédica ou adaptada com quadro balcânico, contendo barras transversais e longitudinais, roldanas e trapézio. $O$ estrado deve ser firme e o colchão macio, permitindo distribuição uniforme do peso do corpo do paciente.

A transferência do paciente da maca para a cama deve ser feita com o máximo cuidado, de forma a evitar a exacerbação da dor devido à mobilização da parte afetada, podendo vir a ocasionar complicaçōes de ordem circulatória.

Nas traçōes de um dos membros inferiores e/ou de membros superiores, simplifica-se o trabalho quando se inicia a transferência pelo lado não traumatizado. O paciente, quando pode, utiliza-se do trapézio da cama, flete o joelho do membro, não lesado, apoiando parte do peso do corpo sobre a perna e o pé e, com movimentos coordenados com o servidor de enfermagem, eleva o corpo e movimenta-se em direção ao centro da cama. 
NEVES, T.A., CAMARGO, C.A. e COMARÚ M.N. - Alguns aspectos que fundamentam a assistência de enfermagem a pacientes em tração. Rev. Bras. Enf.; DF, 29 : 56-63, 1976.

As pessoas que o atendem nesta ocasião, devem ter sua atenção voltada para o foco da fratura, mantendo leve tração na articulação distal; desta forma previne-se a dor, que é decorrente da mobilização dos fragmentos ósseos em contato com as partes moles.

Caso o paciente não tenha condições para ajudar, duas ou mais pessoas deverão transferi-lo para o leito, utilizando para isto lençol da maca. Os movimentos deverão ser seguros e coordenados.

Uma vez acamado, a mesa de cabeceira deverá ser colocada do lado que ofereça melhores condiçōes de uso por parte do paciente.

\section{Instalação da tração}

Para um atendimento rápido e eficiente é necessário que o material a ser utilizado na instalação da tração esteja em condição de uso imediato e em local de fácil acesso.

Esse material varia de acordo com a tração:

a) Tração de esparadrapo - material: - lençol para apoio

- suporte de peso - peso.

b) Tração transesquelética - material:

- cordōes de nylon

- pesos e suporte de peso

- goteiras de Brown ou Thomas

- faixas de algodãozinho

- esparadrapo

- tesoura

- algodão ortopédico

Selecionado o material a ser usado na instalação da tração a mesma deve seguir a prescrição médica quanto à quantidade de peso, angulação, alinhamento e tipo.

Para atuar com segurança e precisão a enfermeira deve aplicar seus conhecimentos de anatomia e fisiologia do sistema músculo-esquelético e os princípios de física (lei do equilíbrio e de biomecânica) nos quais se fundamentam o tratamento por tração.

Ao se instalar a tração deve-se considerar o conforto do paciente, a liberdade necessária para os cuidados higiênicos e a manutenção da tração, conforme a prescrição médica.

Quando se faz uso de goteiras, travesseiros ou alças de suspensão deve-se observar a angulação dos mesmos para que coincidam com as articulaçōes do paciente. A extensão dos planos inclinado e horizontal do aparelho de Brown deve ser proporcional à extensão do membro que sobre eles se apóia.

Enquanto a tração está sendo instalada, a enfermeira deve aproveitar este momento para conversar com o paciente. Ele está passando por uma adaptação da imagem corporal primitiva substituída pela imagem atual; acrescido de estar num ambiente estranho, afastado de seus familiares, sujeito a dor e a incerteza quanto à evolução do tratamento e ao prognóstico. Tudo isto pode levar a alteraçōes de comportamento; portanto necessário se faz estabelecer um meio de comunicação que ofereça segurança ao paciente dando-lhe oportunidade para falar de si, do acidente, dos problemas, olvidar e portanto aliviar a preocupação.

Existe um relato de experiência (4), cuja autoria é de um paciente, no qual ele finaliza dizendo: "esta foi minha experiência e faço um apelo às Marias Isabéis, aos Josés, aos Carlos e às Cristinas, a os "anjos brancos" que passam alguns dias por nossa vida. Nós precisamos de muito calor humano, nós precisamos ser orientados, nós precisamos mais do que nunca de uma verdadeira afeição e não de um quase "mecânico." Como passou a noite "seu" Gilberto?

"Precisamos sentir que há desejo imen- 
NEVES, T.A., CAMARGO, C.A. e COMARUं M.N. - Alguns aspectos que fundamentam a assistência de enfermagem a pacientes em tração. Rev. Bras. Enf.; DF, 29 : 56-63, 1976.

so de nos ajudar a vencer o pavor daqueles penosos momentos."

Há vários fatores de interação que irão afetar a dinâmica da situação e há várias técnicas a serem usadas, sendo primordial atingir o resultado final qual seja: a interação futura da enfermeira $x$ paciente oferecendo a este um ambiente de cordialidade onde o medo seja reduzido e a confiança aumentada.

A pós instalar a tração e revistos os pontos chaves da mesma, tais como: angulação, trajeto do cordão, posição do membro, apoio, segurança dos pesos, a enfermeira fará a apresentação do paciente aos demais companheiros de enfermaria e funcionários. Um ambiente assim trabalhado oferece ao paciente condiçōes de acalmar a ansiedade, relaxar e confiar.

\section{Manutenção da tração}

A tração é considerada parte do tratamento quando atua diretamente no foco de fratura e isto é conseguido mantendo o paciente em posição anatômica. Esta posição, além de interferir no tratamento da fratura, também é causa de deformação ou implicação de processos invalidantes que o paciente pode adquirir por comodidade ou por informação insuficiente sobre sua importância.

Para que o paciente fique em posição anatômica, estando ele em tração, necessário se faz a aplicação de uma força de contra-tração que neutralize a força tracionadora. Estas forças, tracionadora e de contra-tração devem ser constantes em quantidade e direção até que se efetue o calo ósseo.

O tratamento postural deve ser aplicado individual e especificamente a cada paciente, segundo seu diagnóstico, embora existam alguns procedimentos que podem ser aplicados como regra geral a manutenção da posição anatômica do corpo, exemplo: uso de coxim para a correção de rotação de membro, posição de trendelemburg como contra-tração em fratura de membros inferiores, proclive como contra-tração em tração craniana, ação do peso do corpo como contra-tração quando se usa balancim...

Além de mantermos o paciente em posição anatômica, outras medidas devem ser tomadas para evitar modificaçōes que podem interferir no tratamento. As principais interferências são representadas por alteração de peso e desvios de posição. As alteraçōes mais comumente encontradas com relação ao peso são representados por: apoio do suporte sobre alguma barra da cama, diminuição da quantidade de peso (falta de peso), fricção do cordão pela presença de nós ou emendas, roupas sobre o cordão de tração, mal funcionamento das roldanas. Os desvios de posição são evitados pela escolha adequada da cama, colchão, localização da mesa de cabeceira e ação das forças tracionadoras e de contra-tração.

\section{Cuidados higiênicos}

Os cuidados pessoais dispensados ao paciente em tração exigem certas particularidades, para que o tratamento não seja alterado devido à mudança de posição.

Normalmente o paciente em tração tem condiçōes de efetuar a sua higiene e esta atuação deve ser estimulada. 0 material para higiene pode ser colocado ao seu alcance para que inicie o banho lavando e secando: a face, parte anterior do tórax, braços e axilas; os antebraços e as mãos devem ser emergidas na bacia com água para oferecer melhores condiçōes de limpeza e conforto. Para lavar a face posterior do tórax, o paciente deve elevar-se do leito, não se deve permitir que se movimente para o lado, pois estariam sendo deslocadas as forças tracionadoras, o que prejudicaria o tratamento. Para elevar-se, deve usar o trapézio. Quando isto não for possível, duas ou mais pessoas deverão elevá-lo, enquanto outra pessoa lava suas costas. 
NEVES, T.A., CAMARGO, C.A. e COMARU M.N. - Alguns aspectos que fundamentam a assistência de enfermagem a pacientes em tração. Rev. Bras. Enf.; DF, 29 : 56-63, 1976.

A higiene intima deve ser feita com o paciente sobre a comadre; esta é colocada com o auxílio do paciente, que eleva a bacia através da utilização do trapézio. Teremos assim oportunidade de proporcionar ao paciente cuidado higiênico mais satisfatório dando-lhe maior segurança e conforto, ao mesmo tempo que evitamos que se molhe a cama, o que é muito prejudicial para a sua pele.

Perna e pé do membro não tracionado serão emergidos na bacia com água. Este aspecto do cuidado é parcialmente feito pelo paciente, pois dificilmente ele conseguirá alcançar suas extremidades; caso não possa realizar esta parte do seu cuidado deve participar, secando-se.

\section{a) Troca de roupa da cama}

A troca de roupa da cama é feita em 3 etapas:

- o paciente eleva a parte superior do tronco com o auxílio do trapézio ou ele é elevado pelos servidores de enfermagem - com o lençol limpo forra-se a parte do colchão correspondente à cabeceira da cama até a altura da bacia, ao mesmo tempo em que se remove o lençol sujo. Enquanto se prende as bordas do lençol, o paciente descansa;

- a seguir eleva o quadril, com o auxílio do trapézio e se possível do seu membro inferior não comprometido (conforme técnica de transporte anteriormente descrita), sendo o lençol passado até a altura do aparelho de tração;

- continuando a substituição dos lençóis, com um dos antebraços o servidor eleva o aparelho de Brown e com a mão livre forra 0 1/3 inferior do colchão. $O$ lençol sujo é removido e o limpo preso sob o colchão.

O lençol que cobre o paciente não deve interferir na tração, e a extremidade do membro tracionado mantida descoberta para melhor observação.

Em caso de clima frio, o membro tracionado deve ser coberto em separado.
A lavagem da cabeça segue a técnica utilizada para paciente acamados.

\section{b) Eliminações}

A colocação da comadre deve seguir o esquema da elevação da bacia. Utilizando-se um travesseiro como apoio na região dorso-lombar oferece-se mais conforto ao paciente.

Quando o membro tracionado está com goteira de Brown deve-se estar atento para as condiçōes higiênicas da atadura de morim que reveste $o$ aparelho, pois em consequência da proximidade com a região genital pode haver contaminação por urina e fezes.

\section{Aspectos preventivos}

A função da enfermeira não se limita aos culdados anteriormente descritos, mas além destes, também tem como função a prevenção de complicação e o paciente imobilizado está predisposto a tê-las.

Uma das principais complicaçōes oriundas da imobilização é o aparecimento de escaras; rápidas para aparecerem e demoradas para desaparecerem.

O estado nutricional e a idade avançada são fatores que aceleram seu aparecimento sendo estas mais comuns nas regiōes de saliências ósseas. Tentando evitá-las, a enfermeira deve proporcionar apoio a estas áreas através do uso de coxins ou discreta elevação da região.

A região sacra, por exemplo, pode ser protegida utilizando-se coxim de espuma, não muito alto, de aproximadamente $5 \mathrm{~cm}$, para que não interfira no equilíbrio da tração. A compressão do calcâneo sobre o colchão ou sobre a atadura de amorim do aparelho de Brown, pode ser evitada colocando-se um pequeno coxim de espuma sob a região do Tendão de Aquiles. A enfermeira deve estar vigilante para que a área de compressão seja mudada com freqüência. Sua aten- 
NEVES, T.A., CAMARGO, C.A. e COMARU M.N. - Alguns aspectos que fundamentam a assistência de enfermagem a pacientes em tração. Rev. Bras. Enf.; DF, 29 : 56-63, 1976.

ção deve estar voltada também para a posição do outro membro a fím de evitar escaras de calcâneo e deformidade em flexão.

Outro procedimento preventivo é a massagem após o banho, com creme hidratante nas regiōes vuineráveis quais sejam: região do omoplata, cristas llíacas; regiāo sacra, regiāo do trocanter, calcâneo...

Outra complicação conseqüente ao próprio tratamento são as limitações articulares e contraturas musculares que podem afetar não somente o membro em tração como as demais partes do corpo.

Uma das medidas preventivas em tais casos é a estimulação do paciente para o autocuidado, pois ao desenvolver estas atividades estará colocando em movimento os músculos e as articulações.

O controle permanente da posição do paciente no leito pode evitar deformidades tais como: pé equino e rotação do membro. $O$ equinismo pode ser evitado oferecendo apoio plantar fixo ou articulado abrangendo toda a extensão dos pés.

Quando o membro está em tração, pode-se usar malha tubular vestindo pé (como meia), fixa a uma das hastes da cama. Para movimentar a articulação tíbio-tarsica devemos utilizar um cordāo com uma das extremidades amarrada a malha tubular e a outra após passar por roldanas deve ficar ao alcance do paciente. Como os artelhos podem sofrer maior tensão da malha tubular, deve-se acolchoá-los para evitar os prejuízos que esta tensão pode causar. A rotação do membro, quando inferior, segundo Camargo (1) pode ser prevenido com auxílio de rolo de lençol. Este lençol deve ser dobrado no sentido da extensão e a largura da dobra deve corresponder à distância entre a crista ilíaca e a regiāo do planalto tibial de forma que depois de enrolado possa ímpedir a rotação externa da região coxo-femural.

Além destes problemas, a imobilidade no leito pode ocasionar distúrbios digestivos, intestinais e respiratórios. Os distúrbios digestivos e intestinais podem ser evitados oferecendo ao paciente alimentação de fácil digestão, rica em celulose e oferecendo-lhe a comadre nos seus horários habituais de evacuação.

Problemas respiratórios podem ser prevenidos através da utilização de frascos para exercícios respiratórios (sifonagem) ou encher bolas de ar e luvas ou respirar profunda e lentamente. A elevação do tórax que ajudaria bastante na dinâmica respiratória só poderá ser feita após permissão médica, pois interfere na tração.

Outro problema que o paciente em tração está sujeito é o desenvolvimento de infecção ao redor do orifício de entrada e saída do pino de tração. Para prevenir esta infecção deve-se manter cobertos estes orifícios tendo o cuidado de removê-lo periodicamente para verificação do local.

\section{Preparo para alta}

A permanência do paciente em repouso exige menor gasto energético dando ao organismo oportunidade de "diminuir" suas atividades. Ao lado disto, há também diminuição das atividades musculares e articulares. $O$ paciente estando há algum tempo nestas condições ao levantar-se do leito poderá sofrer lipotímia ou dificuldade em manter posição ereta por diminuição de força muscular. Para evitar que isto ocorra o paciente deve ser levantado lentamente, utilizando quando possível a prancha ortostática, caso não haja prancha, pode-se iniciar com travesseiros, aumentando gradativamente a flexão do tórax. Para estar em condições de alta é necessário que o mesmo desempenhe seus cuidados pessoais independentemente.

A familia deve ser informada sobre as limitações de mobilidade do paciente, assim como das suas possibilidades de cuidar-se. Quando é possível fazer uma 
NEVES, T.A., CAMARGO, C.A. e COMARƯ; M.N. - Alguns aspectos que fundamentam a assistência de enfermagem a pacientes em tração. Rev. Bras. Enf.; DF, 29 : 56-63, 1976.

programação para alta o membro da familia mais relacionado com 0 paciente deve ser convidado a vir vê-lo cuidar-se no leito. Se forem apresentados problemas que interfiram nas atividades do paciente no lar, estes devem ser discutidos e procurada uma solução antes que 0 mesmo deixe o hospital.

\section{CONCLUSAO}

O planejamento e execução de técnicas apropriadas de enfermagem, proporcionam aos pacientes submetidos ao tratamento por tração, condiçōes para um restabelecimento mais rápido e livre de sequelas invalidantes ocasionadas pela imo- bilidade no leito ou atuação deficiente daqueles que 0 assistem.

Através de planejamento da assistência de enfermagem a enfermeira terá recursos para verificar se os objetivos estão sendo alcançados; avaliar o trabalho que está sendo realizado com o paciente; avaliar e reformular o programa quando necessário e proceder a supervisão do pessoal de enfermagem com base na assistência que deseja oferecer ao paciente.

Desempenhando o papel de enfermeira clínica ou de educadora, a enfermeira que utiliza-se dos recursos aqui expostos, estará contribuindo para que o paciente reassuma, o quanto antes, seu papel junto à familia e à sociedade.

\section{BIBLIOGRAFIA}

1. CAMARGO, C.A. - O paciente de acidente vascular cerebral e os aspectos de enfermagem em reabilitação. Rev. Bras. Enf.; 28 : 35-42, 1975.

2. CANELA, H.M. - Manual de Clínica Neurológica. São Paulo, Sarvier, 1967.

3. CONNOLL and FISCHER - Promotion of physical confort and safety. Boston University.

4. CORRIJO, G.D. - Eu, paciente! Enf. Novas Dimensões; 1(6): - 309-310, 1976.

5. HORTA, W.A. - Enfermagem: teoria, conceitos, princípios e processos. Rev. Esc. Enf. USP, 8(1): 7-17, março, 1974.
6. KOIZUMI, M.S. - O atendimento de enfermeira em relação à necessidade de auto-imagem. Ene. Novas Dimensões; 1(2): 69-74, 1975.

7. KAMIYAMA, Y e NAKAZAWA, C.K. - Problemas sentidos por pacientes de um hospital particular de São Paulo. Enf. Novas Dimensões; 1(6) : 354-359, 1976.

8. LARSON, C.B. and GOULD, M. - Orthopedic Nursing the C.U. Mosby Company - $17 .^{\circ}$ ed., Saint Louis, 1970.

9. WIEBE, A.M. - Orthopedic in Nursing - W.B. Saunders Company; Philadelphia and London, 1961. 